\title{
Overpressure Identification and Pressure Prediction in Yinggehai Basin
}

\author{
Xianjun Chen \\ China France Bohai Geoservices Co., Ltd., Zhanjiang, China \\ Email: lianghao8@cnooc.com.cn
}

How to cite this paper: Chen, X.J. (2019) Overpressure Identification and Pressure Prediction in Yinggehai Basin. International Journal of Geosciences, 10, 454-462. https://doi.org/10.4236/ijg.2019.104026

Received: March 25, 2019

Accepted: April 27, 2019

Published: April 30, 2019

Copyright $\odot 2019$ by author(s) and Scientific Research Publishing Inc. This work is licensed under the Creative Commons Attribution International License (CC BY 4.0).

http://creativecommons.org/licenses/by/4.0/

\begin{abstract}
The accurate prediction of overpressure is one of the key issues that restrict the effective development of oil and gas resources in the Yinggehai Basin. In this paper, the formation mechanism of overpressure in Yinggehai Basin is studied. Based on this mechanism, the quantitative prediction model and empirical parameters of overpressure are optimized in Yinggehai Basin and applied in engineering. The results show that the formation mechanism of overpressure in the Yinggehai Basin is complicated, and the causes of overpressure in different blocks of basin are different. The eastern block mainly develops loading-type overpressure, while the Ledong block is dominated by unloading high pressure. Different blocks should employ different abnormal high-pressure prediction models. The East block mainly adopts the Eaton method, and the Ledong block mainly utilizes the Bowers method. The empirical parameters of different models can be determined according to the actual drilling conditions. The practical application demonstrates that the abnormal high-pressure prediction error is within $2 \%$, and it is able to satisfy the requirements of on-site engineering.
\end{abstract}

\section{Keywords}

Yinggehai Basin, Overpressure, Formation Mechanism, Pressure Prediction

\section{Introduction}

The Yinggehai Basin is located in the west of the South China Sea and is rich in oil and gas resources. It is the main area for exploration and development in the western South China Sea. However, overpressure is common in this area, and the equivalent mud density is as high as $2.30 \mathrm{~g} / \mathrm{cm}^{3}$, which poses a great challenge for safe drilling operations. Using high-density drilling fluids to ensure that the bottom hole pressure is higher than the pore pressure is the key to pre- 
venting blowout and ensuring drilling security. However, as the drilling mud density window in the area is extremely narrow, the high density drilling fluid is easy to fracture the formation and induce the loss of drilling fluid. Therefore, the prediction accuracy of the pore pressure in the drilling operation of this area is extremely high [1] [2]. In addition, due to sophisticated geological conditions inside the basin, the cause of overpressure is unclear, which further increases the difficulty of pore pressure prediction. Based on this, this paper fully analyzes the overpressure identification method and overpressure quantitative prediction model. On this basis, the formation mechanism of overpressure in Yinggehai Basin is studied, and the pressure prediction model and model parameters are optimized. It is of great significance to reduce the probability of drilling complex situations such as kicks and blowouts, ensure the safety of drilling, timely and effectively develop oil and gas resources in the Yinggehai Basin.

\section{Overpressure Formation Mechanism and Identification Method}

\subsection{Classification of Overpressure Formation Mechanism}

Overpressure is usually generated due to shrinkage of the formation void volume or fluid expansion in the void. At present, there are many formation mechanisms for overpressures found worldwide. The formation of overpressures is usually the result of a combination of multiple mechanisms, but for a given pressure system, there is usually a dominant mechanism. Fundamentally, the overpressure formation of any mechanism requires two prerequisites: 1) a certain volume of void space and fluid; 2 ) good sealing conditions. According to the mechanical relationship in the process of sediment compaction, the formation mechanism of overpressure can be split into four categories: original sediment loading mechanism, reloading mechanism, unloading mechanism and porosity invariant [3]. Among them, the original sediment loading mechanism mainly including under-compacting, which is mainly as the fact that the load applied to the overpressure interval gradually increases or maintains constant during the deposition compaction process, and the rock matrix stress is in the loading process. The reloading mechanism mainly includes the tectonism such as tectonic extrusion, which is mainly due to the tectonic extrusion leads to increasing of the rock matrix effective stress. The unloading mechanism mainly covers the pores fluid expansion caused by hydrocarbon generation, hydrothermal pressure, mineral transformation, fluid migration, etc. The expansion of pore fluid can give rise in the decreasing of rock matrix effective stress.

\subsection{Theory and Method for Identifying Overpressure Formation Mechanism}

For the main hydrocarbon-bearing basins currently discovered, the frequency of constant porosity overpressure is relatively lower. However, the rock pores will undergo different degrees of deformation for the overpressure caused by the 
loading and unloading mechanism. At present, the log data related to pore deformation mainly includes acoustic wave velocity, resistivity and density. Different logging data will have different response characteristics for different overpressure formation mechanisms. Based on this, the formation mechanism of overpressure can be recognized according to the variation law of the logging data.

The pore space inside the rock consists of pores and throats. The density logging data mainly characterizes the volumetric properties of the rock, which is determined by the pores and reflects the porosity of the rock. Acoustic velocity logging and resistivity data characterize the conduction properties of the rock and are determined by the pores and throats. When the rock is in the loading curve, the effective stress acting on the rock matrix is inversely proportional to the porosity, that is, the smaller the effective stress, the larger the porosity, and the smaller the logging density, acoustic velocity and resistivity. Therefore, as for the overpressure of the loading type, the overpressure causes the effective stress to decrease, and the response characteristics of the logging data are that the density, acoustic velocity and resistivity are lower than normal. When the rock is in the unloading curve, the relatively large pores may undergo plastic deformation during diagenesis, and the aspect ratio of the pores is relatively large. The internal pressure of the pores at late period causes the relatively small deformation of the rock pores. Moreover, the overpressure will not cause a large variation in porosity, at the same time. The density logging is basically constant. However, the throat size and aspect ratio of the connected pores are small, and the deformation is more likely to occur than the pores. During the pore internal pressure, the rebound deformation easily occurs at late period, resulting in a change in the conductivity of the rock. Overpressure intervals typically exhibit characteristics of reduced acoustic velocity and resistivity. Therefore, with regard to overpressure of the unloading type, the response characteristic of the logging data is that the density is fundamentally constant, and the acoustic velocity and the resistivity are lower than normal. However, the deviation is smaller than the loading type overpressure. According to the different response characteristics of the loaded and unloaded overpressure logs, the formation mechanism of overpressure can be identified.

\section{Overpressure Quantitative Prediction Model}

Pore pressure refers to the pressure generated by the fluid inside the pores of the rock. When the pore pressure equivalent mud density is higher than $1.2 \mathrm{~g} / \mathrm{cm}^{3}$, it is overpressure. Accurately predicting the magnitude of overpressure is extremely important for safe drilling. At present, there are many methods for predicting pore pressure at home and abroad, among which the four methods of equivalent depth method, empirical coefficient method, Eaton method and Bowers method are widely used [4] [5] [6]

1) Equivalent depth method 
According to the principle of effective stress, when the porosity of the rock is the same, the effective stress acting on the rock matrix is equal. Therefore, after finding the mudstone stratum (point B) with the same porosity as the deep overpressure interval (point A) in the shallow stratum, the pore pressure of the overpressure interval is capable to be calculated by the effective stress of the stratum:

$$
P_{p a}=G_{o a}-\left(G_{o b}-P_{p b}\right) \frac{h_{b}}{h_{a}}
$$

where $G_{0 a}, G_{0 b}$ are the overburden pressure-equivalent mud density of points A and B, respectively, given in $\mathrm{g} / \mathrm{cm}^{3}$, and $P_{p a}, P_{p b}$ are the pore pressure equivalent mud density at points A and B, respectively, given in $\mathrm{g} / \mathrm{cm}^{3} . h_{a}, h_{b}$ are the burial depth of points $A$ and $B$, respectively, given in $\mathrm{m}$.

2) Empirical coefficient method

The empirical coefficient method is applicable to areas where the measured pore pressure data is abundant. Assuming that the measured pore pressure equivalent mud density at each point in the study area is $G_{p}$, the measured sonic differential time is $\Delta t$, and the normal sonic differential time at the point is $\Delta t_{n}$ obtained by the normal trend line equation. The relationship of pore pressure and the sonic differential time is acquired by fitting, which can achieve quantitative calculation of overpressure:

$$
G_{p}=a \frac{\Delta t}{\Delta t_{n}}+b
$$

where $a$ and $b$ are the empirical coefficient, dimensionless.

3) Eaton method

The Eaton method is a calculation method of formation pore pressure commonly used by oilfield companies at home and abroad. It has the characteristics of high calculation accuracy and wide application range. However, the theoretical basis of this method is under-compacting theory. Therefore, it is mainly applied to the overpressure prediction of under-compacting causes. The method can make use of the logging sonic differential time, resistivity, density and Dc index data to calculate the formation pressure, and the calculation principle is the same. The sonic differential time data is as an example to illustrate the expression of the method:

$$
P_{p}=G_{o}-\left(G_{o}-P_{h}\right)\left(\frac{\Delta t_{n}}{\Delta t_{o}}\right)^{N}
$$

where $P_{p}$ is the pore pressure equivalent mud density, given in $\mathrm{g} / \mathrm{cm}^{3}$, and $G_{o}$ is the overburden pressure equivalent mud density, given in $\mathrm{g} / \mathrm{cm}^{3} . P_{h}$ is the normal hydrostatic pressure equivalent mud density, given in $\mathrm{g} / \mathrm{cm}^{3}$, and $\Delta t_{n}$ is the normal trend line sonic differential time of a certain depth shale, given in us/ft. $\Delta t_{o}$ is the sonic differential time of the measured mud shale formation at a given depth, given in $\mathrm{us} / \mathrm{ft}$, and $\mathrm{N}$ is the Easton index.

4) Bowers method 
The Bowers method directly calculates the vertical effective stress by using the original loading and unloading curve equations, and then calculates the pore pressure using the effective stress principle. The advantage of this method is that it does not need to establish a normal trend line, which is more theoretical and avoids the error caused by human experience. At the same time, the method can quantitatively calculate the unloading overpressure.

The loaded overpressure is calculated from the original loading curve of the mud shale:

$$
V=V_{0}+A \sigma_{e v}^{B}
$$

where $V$ is the acoustic velocity, given in $\mathrm{ft} / \mathrm{s}$, and $\sigma_{e v}$ is the vertical effective stress. $V_{0}, A, B$ are the model parameters, which are obtained from the data of the adjacent well or the normal compaction interval.

The unloading type of overpressure is calculated by the unloading curve of the mud shale:

$$
V=V_{0}+A\left[\sigma_{\max }\left(\sigma / \sigma_{\max }\right)^{1 / U}\right]^{B}
$$

In the formula, $\sigma_{\max }$ is determined by the following formula:

$$
\sigma_{\max }=\left(\frac{V_{\max }-V_{0}}{A}\right)^{1 / B}
$$

where $\sigma_{\max }$ and $V_{\max }$ are the maximum vertical effective stress and sonic velocity at the beginning of unloading, and $U$ is the elastoplastic coefficient of mud shale.

\section{The Application of Overpressure Prediction in Yinggehai Basin}

Taking the two blocks of Dongfang and Ledong in Yinggehai Basin as the work area, the formation mechanism and size of overpressure in Yinggehai Basin are studied. The strata encountered in the eastern block are mainly the Ledong Formation, the first interval of Yinggehai Formation, the second interval of the Yinggehai Formation and the Huangliu Formation, and the target layer is located in the Yellow River Formation. In addition to drilling above the strata, some wells in the Ledong block encountered the Meishan Formation in the depths. The target layer of the block is situated at the Huangliu Formation and the Meishan Formation. During the actual drilling process, it is found that there were large overpressures in the two major blocks, which seriously restricted the safe drilling operations on site. In order to ensure the security of on-site operations and improve drilling efficiency, it is necessary to make a major prediction on the overpressure of the two blocks of the East and Ledong blocks in the Yinggehai Basin.

\subsection{Determination of Overpressure Formation Mechanism}

The logging data of the Dongfang D1 well and the Ledong L1 well in the Ying- 
gehai Basin are analyzed and the intersection map of acoustic velocity and density (Figure 1) is drawn. It is found that although the eastern block and the Ledong block belongs to the same basin, however, the log response characteristics are different and they have different overpressure formation mechanisms. The acoustic velocity and density of the eastern blocks are simultaneously lower, which is consistent with the characteristics of the loaded overpressure, and the overpressure caused by the under-compacting. The sound velocity of the block in Ledong is lowered, but the density is basically constant, which is consistent with the characteristics of unloading high pressure, mainly due to hydrocarbon generation or fluid expansion in the pores. Geological studies such as sedimentation rate and hydrocarbon generation in the basin have also confirmed the pressure-forming mechanism of the two blocks in Figure 1.

\subsection{Overpressure Prediction Model and Parameter Optimization}

The principle of four pore pressure prediction methods, namely equivalent depth method, empirical coefficient method, Eaton method and Bowers method, is analyzed. The theoretical basis of equivalent depth method, empirical coefficient method and Eaton method are all under-compacting theory, which is mainly suitable for loaded overpressure prediction, however, Bowers' law is based on the principle of effective stress, which can not only predict the loaded overpressure of under-compacting, but also quantitatively predict the unloading overpressure. The eastern block mainly develops loading-type overpressure. It is theoretically possible to use the equivalent depth method, the empirical coefficient method, the Eaton method and the Bowers method to predict the pore pressure. However, the practical application finds that the shallow layer has no overpressure interval equivalent depth, and the correlation between the pore pressure and the deviation of the sonic differential time is poor, which limits the application of the equivalent depth method and the empirical coefficient method. The Ledong block mainly develops unloading overpressure. In theory, only the Bowers method can be used to predict the pore pressure of the block.

According to the measured pore pressure, drilling engineering and logging data of Dongfang D1 well, the empirical parameters of the Eaton method and Bowers method are determined. From Equation (3), the Eaton method needs to determine two empirical parameters: the normal compaction trend line sonic differential time $\Delta t_{n}$ and the Eaton index N. According to the logging data and drilling engineering data of Dongfang D1 well, the normal compaction trend line of sonic differential time is established. As shown by the red line in Figure 2 , combined with the measured pore pressure and actual drilling, the Eaton index is determined to be 2.5. From formula (4), the key application of Bowers method is to determine the original loading curve of mud shale. According to the test data of D1 well in Dongfang and the actual drilling situation, the original loading curve of mud shale in Dongfang D1 well is determined, as shown by the red curve in Figure 3. Comparing the calculation accuracy and practicability of the Eaton method and the Bowers method in the well, it is the most suitable pore 


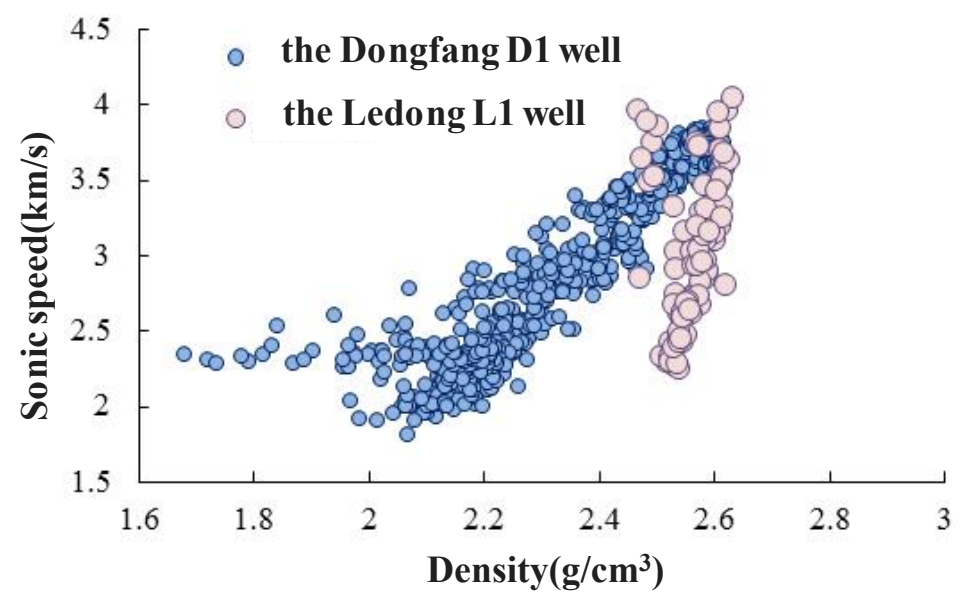

Figure 1. Acoustic velocity-density intersection map of the Yinggehai Basin.

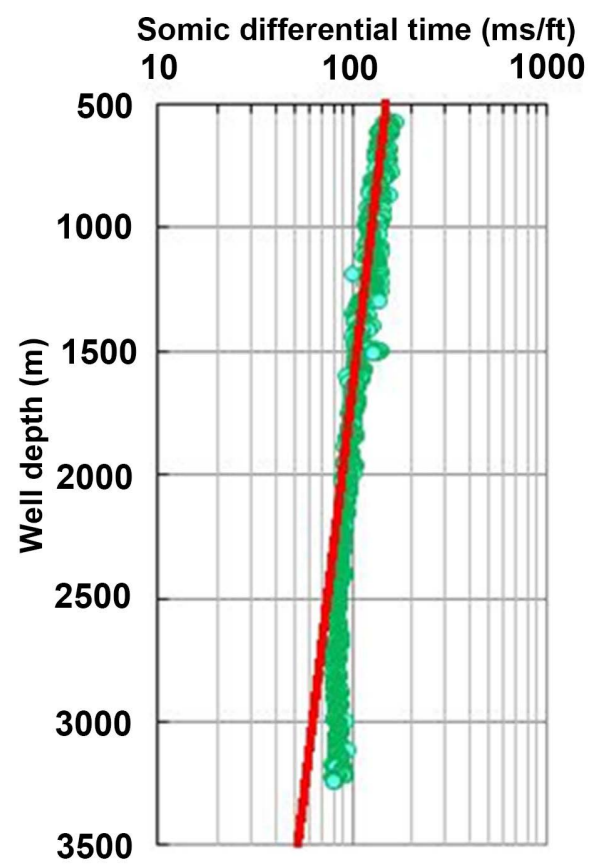

Figure 2. Sonic differential time normal compaction trend line in Dongfang D1 well.

pressure determination method of the Dongfang D1 well is the Eaton method. The same method can be used to determine the original unloading curve of the Ledong L1 mud shale.

\subsection{Application Effect Evaluation of Overpressure Prediction Method}

According to the above method, the pore pressure of Dongfang D2 well in Yinggehai Basin is predicted, and the application effect of the above method is evaluated by combining the measured pore pressure and actual drilling. The Dongfang D2 well is adjacent to the Dongfang D1 well. According to the acoustic velocity and density intersection map of the Dongfang D2 well, the pressure 


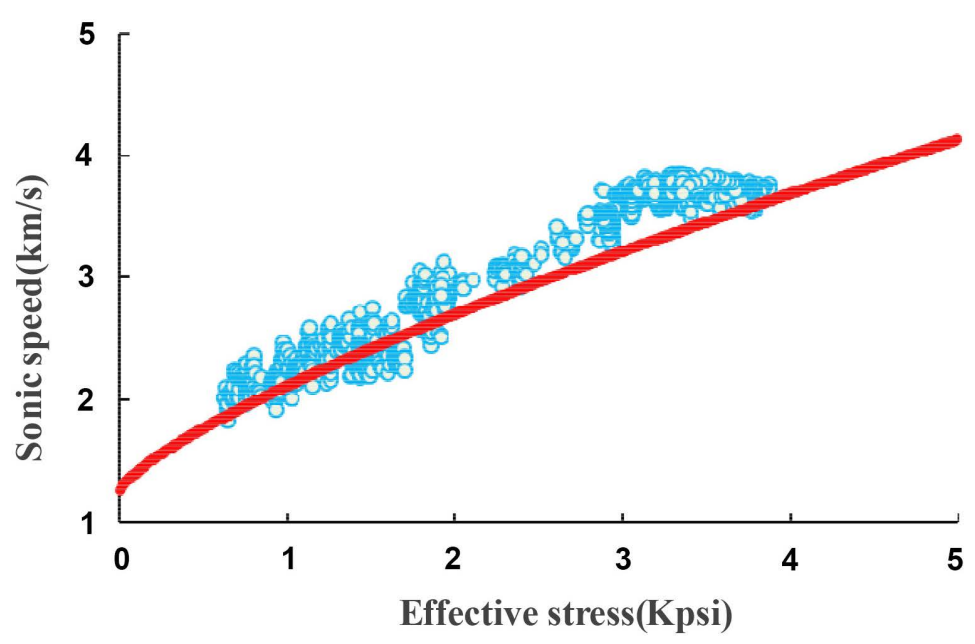

Figure 3. Original loading curve of mud shale in Dongfang D1 well.

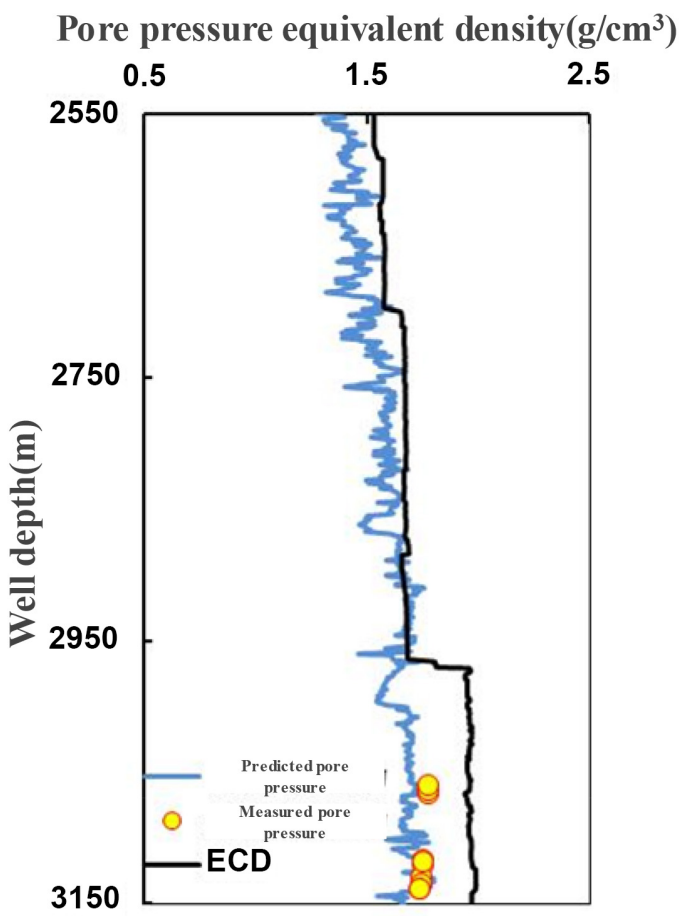

Figure 4. Comparison of pore pressure prediction results with actual conditions of Dongfang D2 well.

formation mechanism of the well is consistent with the Dongfang D1 well. Both of the wells are loaded overpressure, and the Eaton method recommended by the Dongfang D1 well and related model parameters are used. The pore pressure of the Dongfang D2 well is calculated. As shown in Figure 4, compared with the circulating fluid equivalent density (ECD) of the drilling fluid, the ECD of the actual drilling was higher than the predicted pore pressure. No complicated surges, blowouts, etc. are found in the drilling engineering, which is coincided with the actual situation. At the same time, the well is tested for pore pressure 
between $3060 \mathrm{~m}$ and $3150 \mathrm{~m}$. The measured pore pressure equivalent mud density is about $1.74 \sim 1.78 \mathrm{~g} / \mathrm{cm}^{3}$, and the predicted pore pressure equivalent mud density is $1.73 \sim 1.79 \mathrm{~g} / \mathrm{cm}_{3}$. The average prediction error is less than $2 \%$, and the overpressure prediction result satisfies the project requirements.

\section{Conclusions}

1) The formation mechanism of overpressure in the Yinggehai Basin is complicated. The causes of overpressure in different blocks of this basin are different. The eastern block mainly develops loading-type overpressure, while the Ledong block is dominated by unloading high pressure.

2) The overpressure prediction model of the eastern blocks in the Yinggehai Basin mainly adopts the Eaton method, and the Ledong block mainly employs the Bowers method. The empirical parameters of different models can be determined according to the actual drilling conditions. The practical application indicates that the prediction of overpressure accuracy can satisfy field project requirements.

\section{Conflicts of Interest}

The author declares no conflicts of interest regarding the publication of this paper.

\section{References}

[1] Luo, M., Wu, J., Chen, H.D., et al. (2019) Ultra-High Temperature and High Pressure Drilling Technology with Narrow Safety Density Window in Western South China Sea. Petroleum Drilling Techniques, 47, 8-12.

[2] Lin, S.Y., Li, Z., Huang, Y., et al. (2018) The Development and Application of High Performance Water Base Muds for HTHP Wells in Yinggehai Basin. Drilling Fluid \& Completion Fluid, 35, 44-48.

[3] Fan, H.H. (2016) Abnormal Formation Pressure Analysis Method and Application. Science Press, Beijing.

[4] Bowers, G.L. (1995) Pore Pressure Estimation from Velocity Data: Accounting for Overpressure Mechanisms besides Under-Compaction. SPE Drilling \& Completion, 10, 89-95. https://doi.org/10.2118/27488-PA

[5] Eaton, B.A. (1972) The Effect of Overburden Stress on Geo-Pressure Prediction from Well Logs. Journal of Petroleum Technology, 24, 929-934.

https://doi.org/10.2118/3719-PA

[6] Wang, Z.F. and Luo, X.R. (2004) Pressure Prediction and Monitoring Technology of HTHP Formation in Yinggehai Basin. Petroleum Industry Press, Beijing. 